\title{
To the problem 5 of emplacement of triangular geometric net on the sphere
}

\author{
Vladimir Travush ${ }^{1}$, Vasilij Antoshkin ${ }^{2, *}$, Artem Konovalov ${ }^{2}$ \\ ${ }^{1}$ RAABS, BolshayaDmitrovka 24-1,Moscow,107031, Russia \\ ${ }^{2}$ Mordovian State University, Bolshevistskaya 68, Saransk,430005, Russia
}

\begin{abstract}
The sphere creates the minimal surface of enclosing structures and has unique resource saving qualities which makes it indispensable in the construction of "smart buildings». One of the methods of formation of triangular networks in the spherewas investigated. Conditions of the problem of locating a triangular network in the area were established. The evaluation criterion of solution effectiveness of the problem is the minimum number of type-sizes of dome panels, the possibility of pre-assembly and prestressing. The solution of the problem of the triangular network emplacement in a compatible spherical triangle on the sphere variant was provided. The problem of the emplacement of regular and irregular hexagons on the sphere, inscribed in a circles, i.e., flat figures or composed ones of spherical triangles with minimum dimensions of the ribs, has an effective solution in the form of a network, formed on the basis of minimum radii circles, i.e., circles on a sphere obtained by the touch of three adjacent circles whose centers are at the shortest distance from each other. The optimization of triangular geometric network on a sphere on the criterion of minimum sizes of elements can be solved by emplacementinthe system the irregular hexagons inscribed in circles of minimal sizes, the maximum of regular hexagons.
\end{abstract}

\section{Introduction}

The sphere creates the minimal surface of enclosing structures and has unique resource saving qualities, which makes it indispensable in the construction of «smart buildings». The problem of the emplacement of regular and irregular hexagons on the sphere, inscribed in a circles, i.e., flat figures or composed ones of spherical triangles (See Fig. 1) with minimum dimensions of the ribs, has an effective solution in the form of a network, formed on the basis of minimum radii circles, i.e., circles on a sphere obtained by the touch of three adjacent circles whose centers are at the shortest distance from each other. [1-3, 5-8]. The

\footnotetext{
*Corresponding author: antovd@mail.ru
} 
emplacement of irregular and regular hexagons inscribed in a circle, will be implemented at the example of cutting in the form of a 2000-poluhedron (Fig. 1).

For the solution of the problem (Fig. 2) a spherical triangle of $\mathrm{ABC}$ will be considered, and also a spherical rectangular triangle of $\mathrm{O}_{2} \mathrm{NO}_{11}$ with a leg arch, equal to total radius $\rho_{1}$ and $\rho_{2}$. There is a rectangular spherical triangle with internal corners of 90 and 60 degrees and a leg arch, equal $a$.It is required to determine sizes of radii $\rho_{1}$ and $\rho_{2}$ between the $\mathrm{O}_{11}, \mathrm{O}_{12}$ and $\mathrm{O}_{2}$ centers of circles and, thus, position of all centers of circles of the first two rows of hexagons will be defined.

For definition of the centers of hexagons of equal radii some additional requirements to an arrangement of three circles will be entered. First, setting that the circle, with the center in a point of $\mathrm{O}_{11}$ crosses the party arch perpendicularly and a bisector of $\mathrm{O}_{2}$ of an isosceles triangle ofO $\mathrm{O}_{11} \mathrm{O}_{2} \mathrm{O}_{12}$ crosses the party arch of $\mathrm{O}_{11} \mathrm{O}_{12}$ in two equal parts.

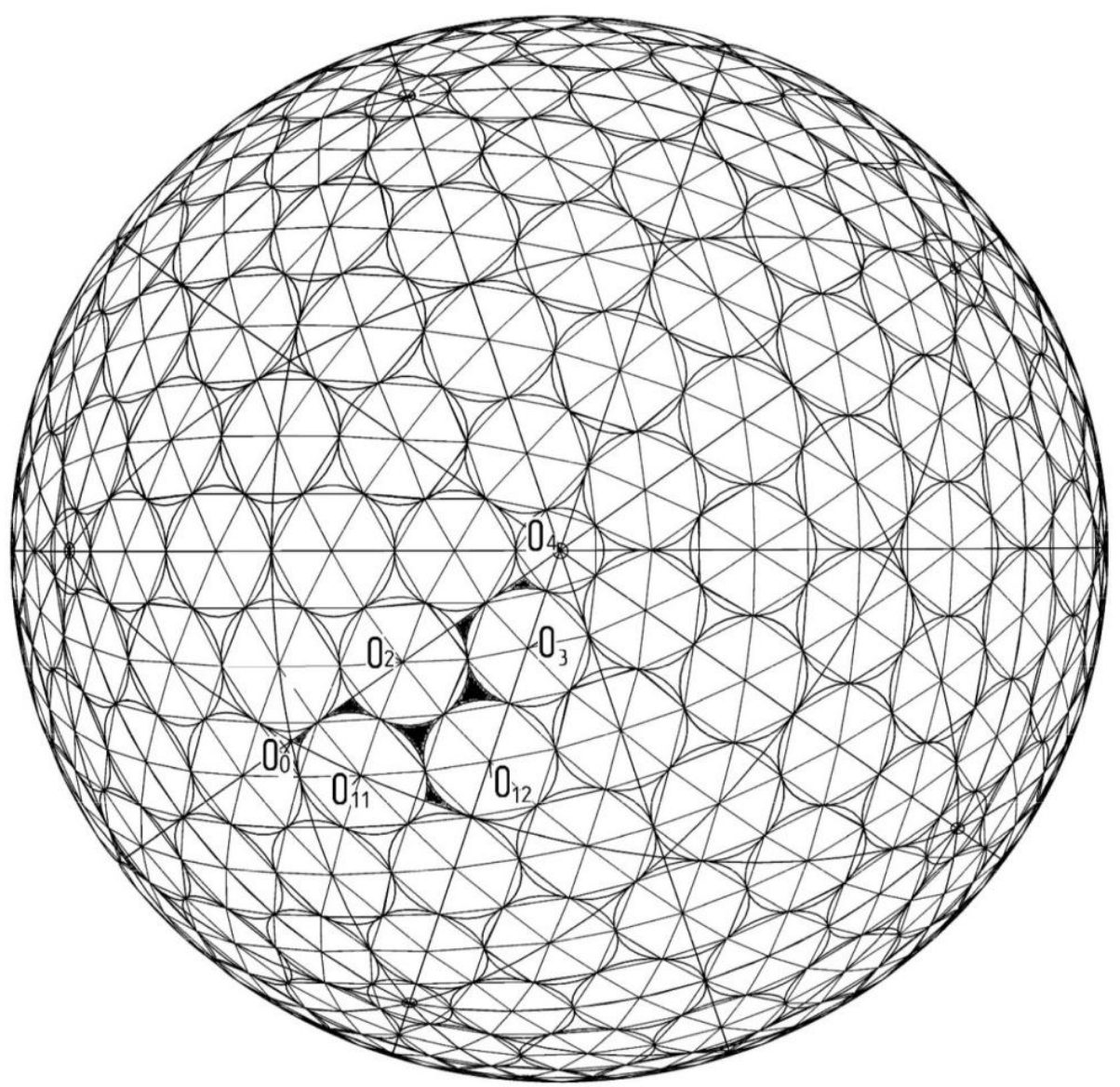

Fig.1.The sphere, made up of compatible spherical triangles (segments, representing $1 / 6$ of the brink of the icosahedron), by cutting a triangular network of 2000-polyhedron having 14 elements of typesizes or 5 type-sizes of mounting panels (altogethertype-sizes -11); $\mathrm{O}_{0}$ isthe center of the fringe of the icosahedron and the panel in the form of an equilateral triangle on the sphere; $\mathrm{O}_{11}, \mathrm{O}_{12}, \mathrm{O}_{2}, \mathrm{O}_{3}$, $\mathrm{O}_{4}$ are the centers of the mounting panels in the form of flat hexagons and pentagons in a segment of the internal angles of $36,90,60^{\circ}$ for solving the optimization problem of the triangular network. 


\section{To the problem 5 of emplacement of triangular geometric net on the sphere}

Previously it is needed to determine parameters into this spherical triangle of $\mathrm{ABC}$. It was set that internal corners of a triangle $\mathrm{B}=60^{\circ}, \mathrm{C}=90^{\circ}, \mathrm{CO}_{12}=\rho_{1}, \mathrm{O}_{11} \mathrm{O}_{12}=2 \rho_{1}, \mathrm{O}_{11} \mathrm{O}_{2}=$ $=\mathrm{O}_{12} \mathrm{O}_{2}=\rho_{1}+\rho_{2}$. Using known expressions of the parts of a rectangular spherical triangle through tangents of legs and a hypotenuse, the hexagons will be received.

$$
\cos A=\cos a \sin \mathrm{B}, \cos A=\frac{\sin \mathrm{B}}{\sqrt{1+\operatorname{tg}^{2} \mathrm{a}}}, \cos A=\frac{\sqrt{3}}{2 \sqrt{1+\operatorname{tg}^{2} a}}
$$

It is needed to enter the designation of $\mathrm{O}_{11} \mathrm{C}=x$. Then $\mathrm{O}_{11} \mathrm{~B}=\mathrm{a}-x$, from a triangle of $\mathrm{O}_{11}$ BA connection of size $x$ and required radius $\rho_{1}$ will be determined:

$$
\frac{\sin r_{o}}{\sin 60^{\circ}}=\frac{\sin (a-x)}{\sin (A-X)}
$$

From a triangle of $\mathrm{O}_{11} \mathrm{O}_{12} \mathrm{C}$ also the interrelation of sizes $x$ and $\rho_{1}$ will be defined:

$$
\begin{aligned}
& 2 \cos ^{2} \rho_{1}=\cos \rho_{1} \cos x+1 . \\
& \sin \rho_{1}=\sin (A-X) \sin r_{o}
\end{aligned}
$$

Thus, the system of the equations (2) and (3) allows determining the required radius $\rho_{1}$ of the equation:

$$
\begin{aligned}
& \sin 60^{\circ} \sin (a-x)=\sin \rho_{1} \\
& \left(\sin 60^{\circ} \sin (a-x)\right)^{2}=1-\cos ^{2} \rho_{1}
\end{aligned}
$$

Solving it, we come to a ratio:

$$
\cos ^{2} \rho_{1}-\sin ^{2} \rho_{1}=\cos \rho_{1} \cos x
$$

The ratio will be put in the first equation (4)

$$
\cos ^{2} \rho_{1}=1-0.75 \sin ^{2}(a-x)
$$

It's gotten to:

$$
\begin{gathered}
2\left(1-0.75 \sin ^{2}(a-x)\right)=\cos x \sqrt{1-0.75 \sin ^{2}(a-x)}+1 \\
\left(1-\frac{1.5}{1+\operatorname{ctg}^{2}(a-x)}\right)^{2}=\cos ^{2} x\left(1-\frac{+0.75}{1+\operatorname{ctg}^{2}(a-x)}\right) ; \\
\left(\operatorname{ctg}^{2}(a-x)-0.5\right)^{2}=\cos ^{2} x\left(0.25+\operatorname{ctg}^{2}(a-x)\right)\left(1+\operatorname{ctg}^{2}(a-x)\right) ; \\
\left(1-0.5+\left(\frac{1+\operatorname{tg} a \operatorname{tg} x}{\operatorname{tg} a-\operatorname{tg} x}\right)^{2}\right)^{2}= \\
=\cos ^{2} x\left(0.25+\left(\frac{1+\operatorname{tg} a \operatorname{tg} x}{\operatorname{tg} a-\operatorname{tg} x}\right)^{2}\right)\left(1+\left(\frac{1+\operatorname{tg} a \operatorname{tg} x}{\operatorname{tg} a-\operatorname{tg} x}\right)^{2}\right)
\end{gathered}
$$

Substitute $1+\operatorname{tg}^{2} x=1 / \cos ^{2} x$; 


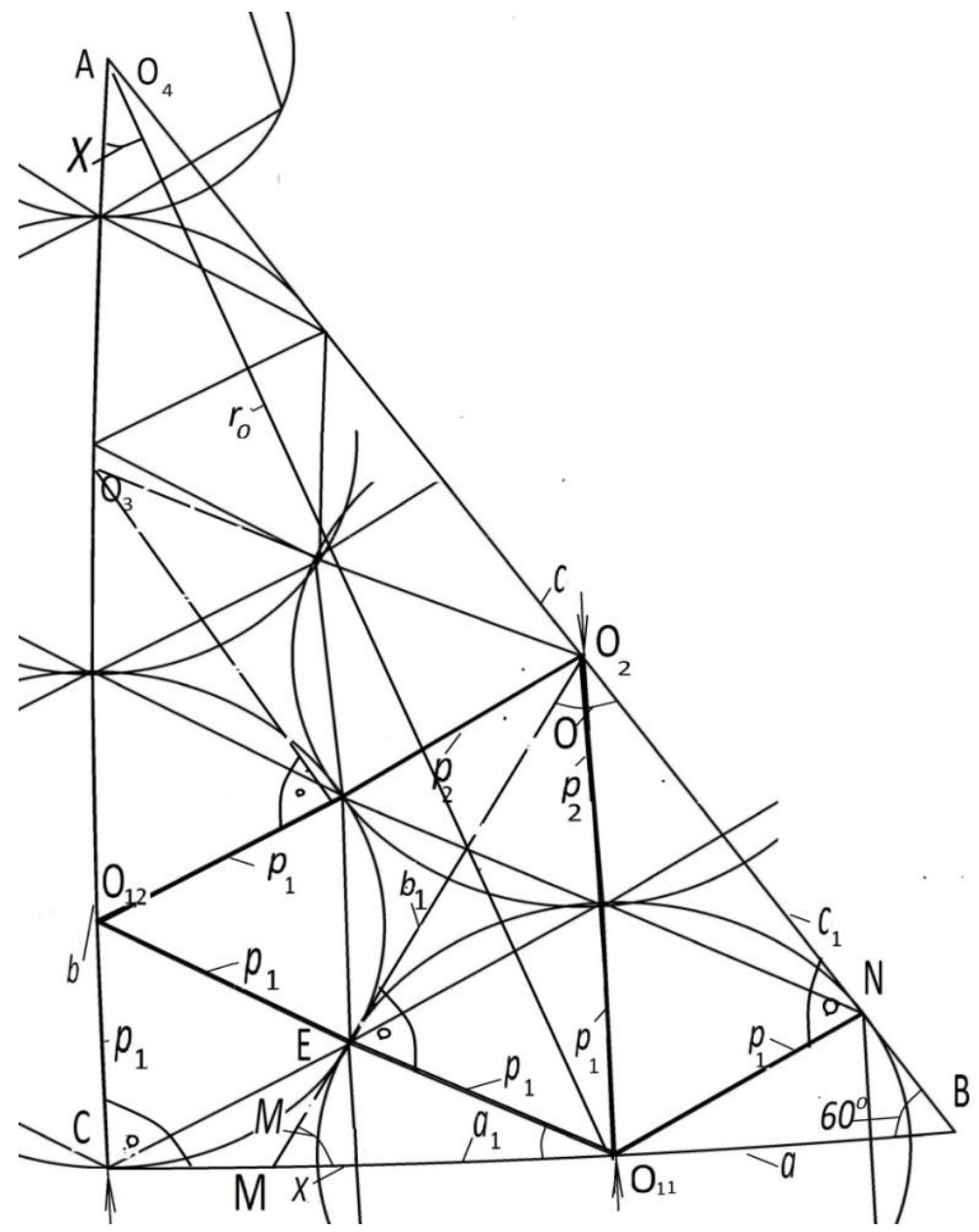

Fig.2.Definition of the $\mathrm{CO}_{11}, \mathrm{O}_{12}$ and $\mathrm{O}_{2}$ centers of hexagons of different radii in a spherical triangle (segment) with internal corners of $90-60^{\circ}$ degrees for cutting in a look a 2000 -polyhedron at the solution of a problem of optimization of a triangular network by means of symmetry and properties of circles and the main lines of the sphere (the main lines are axes within a spherical segment).

$$
\begin{gathered}
\left(1+\operatorname{tg}^{2} x\right)\left(-0.5(\operatorname{tg} a-\operatorname{tg} x)^{2}+(1+\operatorname{tg} a \operatorname{tg} x)^{2}\right)^{2}= \\
=\left(0.25(\operatorname{tg} a-\operatorname{tg} x)^{2}+(1+\operatorname{tg} a \operatorname{tg} x)^{2}\right)\left((\operatorname{tg} a-\operatorname{tg} x)^{2}+(1+\operatorname{tg} a \operatorname{tg} x)^{2}\right) .
\end{gathered}
$$

Substitute $t=\operatorname{tg} a ; k=\operatorname{tg} x$.

$$
\begin{gathered}
\left(1+k^{2}\right)\left(-0.5(t-k)^{2}+(1+t k)^{2}\right)^{2}= \\
\left.=\left(0.25(t-k)^{2}+(1+t k)^{2}\right)\left((t-k)^{2}+(1+t k)^{2}\right)\right) ; \\
\left(1+k^{2}\right)\left(-0.5 t^{2}+t k-0.5 k^{2}+1+2 t k+t^{2} k^{2}\right)^{2}= \\
=\left(0.25 t^{2}-0.5 t k+0.25 k^{2}+1+2 t k+t^{2} k^{2}\right)\left(t^{2}-2 t k+k^{2}+1+2 t k+t^{2} k^{2}\right) ; \\
\left(1+k^{2}\right)\left(1-0.5 t^{2}+3 t k+\left(t^{2}-0.5\right) k^{2}\right)^{2}=
\end{gathered}
$$




$$
\begin{gathered}
=\left(1+0.25 t^{2}+1.5 t k+\left(t^{2}+0.25\right) \mathrm{k}^{2}\right)\left(1+t^{2}+\left(t^{2}+1\right) k^{2}\right) \\
\left(1+k^{2}\right)\left(\left(1-0.5 t^{2}+3 t k\right)^{2}+2\left(1-0.5 t^{2}+3 \mathrm{t} k\right)\left(t^{2}-0.5\right) k^{2}+\right. \\
\left.+\left(t^{2}-0.5\right)^{2} k^{4}\right)=\left(1+0.25 t^{2}+1.5 t \mathrm{k}+\left(t^{2}+0.25\right) k^{2}\right)\left(1+t^{2}+\left(t^{2}+1\right) k^{2}\right) \\
\left(t^{2}-0.5\right)^{2} k^{6}+6 t\left(\mathrm{t}^{2}-0.5\right) k^{5}+ \\
+\left(\left(t^{2}-0.5\right)^{2}+9 t^{2}+2\left(1-0.5 t^{2}\right)\left(t^{2}-0.5\right)-\left(t^{2}+1\right)\left(t^{2}+0.25\right)\right) k^{4}+ \\
+\left(6 t\left(t^{2}-0.5\right)+6 t\left(1-0.5 t^{2}\right)-1.5\left(t^{2}+1\right)\right) k^{3}+ \\
+\left(\left(9 t^{2}+2\left(1-0.5 t^{2}\right)\left(t^{2}-0.5\right)+\left(1-0.5 t^{2}\right)^{2}-\left(t^{2}+1\right)\left(1+0.25 t^{2}\right)-\right.\right. \\
\left.-\left(t^{2}+0.25\right)\left(1+t^{2}\right)\right) k^{2}+\left(\left(6 t\left(1-0.5 t^{2}\right)-1.5\left(1+t^{2}\right) \mathrm{t}\right) k+\left(1-0.5 t^{2}\right)^{2}-\right. \\
-\left(1+t^{2}\right)\left(1+0.25 t^{2}\right)=0
\end{gathered}
$$

By accepting $a=20.9051629^{\circ}$, it's gotten to:

$$
t=\operatorname{tg} a=0.381966127 ; k=\operatorname{tg} \mathrm{x}=0.2226474416 .
$$

$0.125388143656377 t^{6}-0.811529534406437 t^{5}+0.328271320286217 t^{4}+$

$+0.656541386438659 t^{3}-0.125387586261266 t^{2}+1.4680709208451 t-$

$-0.328270762893435=0$.

Which is gotten from the relation:

$$
\sin 60^{\circ} \sin (a-x)=\sin \rho_{1}, \quad \rho_{1}=7.22758597789^{\circ}
$$

\section{Remark}

It should be noted that the condition of a contact of two circles with the centers in $\mathrm{O}_{11}$ points $\mathrm{O}_{2}$ is respectively possible, perhaps in the case, if the angle $\mathrm{O}_{2} \mathrm{O}_{11} \mathrm{~B}$ isa right angle.

For finding of radius $\rho_{2}$ second circles a triangle of $\mathrm{MO}_{2} \mathrm{O}_{11}$ will be considered. Application of the theorem of cosines gives the following ratio.

$$
\cos \left(\rho_{1}+\rho_{2}\right)=\cos a_{1} \cos b_{1}+\sin a_{1} \sin b_{1} \cos M
$$

From the triangle $\mathrm{MO}_{2} \mathrm{~B}$ :

$$
\cos O=-\cos \mathrm{M} \cos 60^{\circ}+\sin \mathrm{M} \sin 60^{\circ} \cos \left(a-x+a_{1}\right)
$$

where $a_{1}=\mathrm{MO}_{11}, b_{1}=\mathrm{MO}_{2}$ :

From triangle $\mathrm{CO}_{11} \mathrm{O}_{12}$, expressing the cosine of the angle $\mathrm{O}_{11}$ through the tangents, the following equation will be found:

$$
\cos O_{11}=\frac{\operatorname{tg} x}{\operatorname{tg} 2 \rho_{1}}
$$

where the internal angle $\mathrm{O}_{11}=\mathrm{CO}_{11} \mathrm{O}_{12}=\mathrm{MO}_{11} \mathrm{E}$.

All sizes in this expression are determined, excepting the angletg $a_{1}$.

Followed from a rectangular triangle of $\mathrm{MO}_{11} \mathrm{E}$ : 
Denote the angle $\mathrm{EMO}_{11}$ by $\mathrm{M}$ :

$$
\operatorname{tg} a_{1}=\frac{\operatorname{tg} \rho_{1}}{\cos 0_{11}}
$$

$$
\sin \mathrm{M}=\frac{\sin \rho_{1}}{\sin a_{1}}
$$

First, it should be used the ratio of the triangle $\mathrm{MO}_{2} \mathrm{~B}$ :

$$
\cos O=\cos \mathrm{M} \cos 60^{\circ}+\sin \mathrm{M} \sin 60^{\circ} \cos \left(a-x+a_{1}\right)
$$

Then the ratio for the triangle $\mathrm{O}_{11} \mathrm{O}_{2} \mathrm{~B}$ should be applied:

$$
\frac{\sin b_{1}}{\sin 60^{\circ}}=\frac{\sin \left(a-x+a_{1}\right)}{\sin 0}
$$

Thus, $\rho_{2}$ of the second circle radius from the equation(20)will be determined:

$$
\cos \left(\rho_{1}+\rho_{2}\right)=\cos a_{1} \cos b_{1}+\sin a_{1} \sin b_{1} \cos \mathrm{M}
$$

From where it will be received:

$\rho_{1}=7.227585978 ; \rho_{2}=5.905344387^{\circ}$. To solve the equation (18) it was used free software Sclab 5.4.1 - The free platform for Numerical Computation (analogue Matlab) [15].

For a given position of the center of the first rows of hexagons inscribed in a circle, the angles change, and hence, the optimization are possible only for centered hexagons $\mathrm{O}_{2}-\mathrm{O}_{3}[8$, 9, 16-22].

\section{Conclusions}

These solutions allow realising the algorithms of approximation the triangular geometric network with the maximum number of regular hexagons and preparing the options for optimization of sphere cutting.

\section{References}

1. V. D. Antoshkin, V.T.Erofeev, V. I.Travush, V.I.Rimshin, V. L.Kurbatov, Modern Applied Science, 3, 46-50 (2015)

2. V. D. Antoshkin, Regional architecture and engineering,3 (24), 112-121 (2015)

3. V. D.Antoshkin, S. S. Gudozhnikov, O. I. Perfilieva, I. V. Erofeeva, Actual problems of architecture and construction. Proceedings of the Thirteenth International scientifictechnical conference: in 12(2), 4-15 (2014)

4. V. D. Antoshkin., V. I. Nikonov, Fundamental research,11-8, 1669-1673 (2014)

5. V.D. Antoshkin, A.G. Konovalov, Ogarev-Online, 13 (54), 6-9 (2015)

6. V.D.Antoshkin, G.V. Kurbakov, V.S. Bochkin, StredoevropskyVestnik pro Vedu a Vyzkum,83.1 (2015)

7. D. V. Alekseevskii, E.B. Vinberg, D.I. Solodovnikov,Geometry of spaces of constant curvature. Results in science and technology.Current problems in mathematics.Fundamental Directions (VINITI, 1998) 
8. V. D. Antoshkin, V. G. Kurganski,StredoevropskyVestnik pro Vedu a Vyzkum, 83.2 (2015)

9. V. T. Erofeev, O. V.Startsev, V. D. Antoshkin, S. S. Gudozhnikov, E. G. Smolkin, I. V. Boldin, A. Y. Makhankov, The change in strength of wood in conditions of high humidity. Basic research, 9-12, 2630-2638 (2014)

10. W. Lienhard, Elem. Math, 66 (2), 74-82 (2011).

11. V. F. Manukhov, A. S. Turchin, Glossary of geodetic terms: proc. Manual (PublishingMord. Univ., Saransk, 2005).

12. B. V. Miryaev, Regional architecture and engineering, 3, 122-125 (2012)

13. A. G. Konovalov, V. D. Antoshkin, Actual problems of architecture and construction materials of the Proceedings of the Thirteenth International scientific-technical conference: in 14(2), 48-53 (2015)

14. G.A.Korn, T.M.Korn. Mathematical Handbook for Scientists and Engineers, 1151

(2000)

15. Software Scilab 5.4.1 - The free platform for Numerical Computation/ Date Views 06.17.2014 / www. softkumir.ru/index

16. S. Çarbaş, M. P. Saka, Asian journal of civil engineering (building and housing) 10(1), 97-112 (2009)

17. A. Behzad, M. Hamid, A.Amran, Applied Mechanics and Materials. 110-116(39), 956-964 (2012)

18. A. Lopez, I. Puente and M. A. Serna, A new beam-element. „Proceedwgs of the international semposium". Warsaw, Poland, 24-28(6), 639-644 (2002)

19. V. I. Travush, V. D. Antoshkin, , I. V. Yerofeyeva,, D. V. Antoshkin, Team spherical shell. Patent RU No 2564545 07/28/2014

20. V. I. Travush, V. D. Antoshkin, V. T. Erofeyev, S. S.Gudozhnikov,Construction and reconstruction, 6 (50), 36-48(2013)

21. V. I. Travush, V. D.Antoshkin, V. T.Erofeev, MATEC Web of Conferences, 86 (2016)

22. V. I. Travush, V. D. Antoshkin, V. T. Erofeev, MATEC Web of Conferences, 86 (2016) 